\title{
Specially Structured Three Stage Flowshop Scheduling to Minimize the Rental Cost
}

\author{
Deepak Gupta, Sameer Sharma, and Shashi Bala
}

\begin{abstract}
This paper pertain to a specially structured njobs, 3- machines flow shop scheduling in which the processing times are associated with probabilities to minimize the rental cost of the machines. Further the expected processing times are not random but bear a well defined relationship to one another. Many heuristics approaches have already been discussed in literature to minimize the makespan. But, in many cases minimization of makespan does not lead to minimum rental cost of the machines under a specified rental policy. The present work is an attempt to develop a heuristic algorithm to minimize the rental cost of the machines under a specified rental policy and will provide an important tool for the decision makers.
\end{abstract}

Index Terms-Specially structured flow shop scheduling; processing time; rental cost; idle time;makesspan; utiliztaion time.

\section{INTRODUCTION}

Scheduling problems have been extensively investigated by many researchers with an aim to determine the sequence for processing jobs on a given set of machines. Its importance and relevance to industry has promoted researchers to study it from different perspectives. Flowshop is the classical and most studied manufacturing environment in scheduling literature. Makespan and total flow time are commonly used performance measure in flowshop scheduling literature. Only some efforts had been made to minimize the rental cost of the machines. Minimization of makespan does not always lead to minimum rental cost. Further, In most of literature the processing time of jobs is considered to be random. But there are significant situations in which the processing times are not random, but follow some well defined structural conditions. One of the earliest results in flowshop scheduling theory is an algorithm given by Johnson's (1954) for scheduling jobs in a two, three stage machine flowshop to minimize the time at which all jobs are completed. Gupta, J.N.D (1975) gave an algorithm to find the optimal schedule for specially structured flowshop scheduling. The work was developed by Ignall \& Scharge (1965), Bagga (1969), Szware (1977), Maggu \& Das (1981), Singh, T.P.(2005), Gupta Deepak (2005) etc. by considering the various parameters. Narain (2005)

Manuscript received March 14, 2012; revised April 23, 2012.

D. Gupta and S. Bala are with Department of Mathematics, M. M. University, Mullana, Ambala, India (email: samsharma31@yahoo.com).

S. Sharma is with Department of Mathematics, D.A.V.College, Jalandhar, Punjab, India. studied a problem to obtain a sequence which gives minimum possible rental cost while minimize total elapsed time under pre-defined rental policy.

Gupta \& Sharma et al (2012) studied specially structured two stage flow shop problem to minimize the rental cost of the machines under pre-defined rental policy in which the processing time have been associated with probabilities. The present paper is an attempt to develop a heuristic algorithm to minimize the rental cost for three stages specially structured flow shop scheduling under the specified rental policy.

\section{PRACTICAL SituATION}

Various practical situations occur in real life when one has got the assignments but does not have one'sown machine or does not have enough money or does not want to take risk of investing huge amount of money to purchase machine. Under such circumstances, the machine has to be taken on rent in order to complete the assignments. In his starting career, we find a medical practitioner does not buy expensive machines say X-ray machine, the Ultra Sound Machine, Rotating Triple Head Single Positron Emission Computed Tomography Scanner, Patient Monitoring Equipment, and Laboratory Equipment etc., but instead takes on rent. Rental of medical equipment is an affordable and quick solution for hospitals, nursing homes, physicians, which are presently constrained by the availability of limited funds due to the recent global economic recession. Renting enables saving working capital, gives option for having the equipment, and allows upgradation to new technology.

\section{NOTATIONS}

$S \quad$ : Sequence of jobs $1,2,3, \ldots, n$

$S_{k}$ : Sequence obtained by applying Johnson's procedure, $\mathrm{k}=1,2,3$,

$M_{j} \quad:$ Machine $\mathrm{j}, \mathrm{j}=1,2,3$

$a_{i j} \quad$ : Processing time of $i^{t h}$ job on machine $M_{j}$

$p_{i j} \quad$ : Probability associated to the processing time $a_{i j}$

$A_{i j} \quad$ : Expected processing time of $i^{\text {th }}$ job on machine $M_{j}$

$t_{i j}\left(S_{k}\right)$ : Completion time of $i^{\text {th }}$ job of sequence $S_{k}$ on machine $M_{j}$

$I_{i j}\left(S_{k}\right)$ : Idle time of machine $M_{j}$ for job $i$ in the sequence $S_{k}$

$U_{j}\left(S_{k}\right)$ : Utilization time for which machine $M_{j}$ is required for sequence $S_{k}$ of jobs

$R\left(S_{k}\right)$ : Total rental cost for the sequence $S_{k}$ of all the 
machine

$C_{i} \quad$ : Renal cost of $i^{\text {th }}$ machine.

$C T\left(S_{k}\right) \quad$ : Total completion time of the jobs for the sequence $S_{k}$.

\section{DEFINITION}

Completion time of $i^{\text {th }}$ job on machine $M_{j}$ is denoted by $t_{i j}$ and is defined as:

$t_{i j}=\max \left(t_{i-1, j}, t_{i j-1}\right)+a_{i j} \times p_{i j}$ for $j \geq 2$.

$=\max \left(t_{i-1, j}, t_{i, j-1}\right)+A_{i, j}$, where $A_{i, j}=$ Expected processing time of $i^{\text {th }}$ job on $j^{\text {th }}$ machine.

\section{Rental Policy}

The machines will be taken on rent as and when they are required and are returned as and when they are no longer required. i.e. the first machine will be taken on rent in the starting of the processing the jobs, $2^{\text {nd }}$ machine will be taken on rent at time when $1^{\text {st }}$ job is completed on the $1^{\text {st }}$ machine and the $3^{\text {rd }}$ machine is taken on rent when the $2^{\text {nd }}$ job is completed on $2^{\text {nd }}$ machine.

\section{PROBLEM ForMULATION}

Let some job $i(i=1,2, \ldots \ldots \ldots, \mathrm{n})$ is to be processed on three machines $M_{j}(j=1,2,3)$ under the specified rental policy P. Let $a_{i j}$ be the processing time of $i^{\text {th }}$ job on $j^{\text {th }}$ machine with probabilities $p_{i j}$. Let $A_{i j}$ be the expected processing time of $i^{\text {th }}$ job on $j^{\text {th }}$ machine such that either $A_{j 2} \leq A_{i 1}$ or $A_{j 2} \leq A_{i 3}$ for all values of $i, j$. Our aim is to find the sequence $\left\{S_{k}\right\}$ of the jobs which minimize the rental cost of the machines.

TABLE I: The Mathematical Model of THE Problem in MATRIX

\begin{tabular}{|c|c|c|c|c|c|c|}
\hline Jobs & \multicolumn{2}{|c|}{ Machine $M_{1}$} & \multicolumn{2}{|c|}{ Machine $M_{2}$} & \multicolumn{2}{|c|}{ Machine $M_{3}$} \\
\hline$I$ & $a_{i 1}$ & $p_{i 1}$ & $a_{i 2}$ & $p_{i 2}$ & $a_{i 3}$ & $p_{i 3}$ \\
\hline 1 & $a_{11}$ & $p_{11}$ & $a_{12}$ & $p_{12}$ & $a_{13}$ & $p_{13}$ \\
\hline 2 & $a_{21}$ & $p_{21}$ & $a_{22}$ & $p_{22}$ & $a_{23}$ & $p_{23}$ \\
\hline 3 & $a_{31}$ & $p_{31}$ & $a_{32}$ & $p_{32}$ & $a_{33}$ & $p_{33}$ \\
\hline- & - & - & - & - & - & - \\
\hline$n$ & $a_{n 1}$ & $p_{n 1}$ & $a_{n 2}$ & $p_{n 2}$ & $a_{n 3}$ & $p_{n 3}$ \\
\hline
\end{tabular}

Mathematically, the problem is stated as: Minimize $R\left(S_{k}\right)=\sum_{i=1}^{n} A_{i 1} \times C_{1}+U_{2}\left(S_{k}\right) \times C_{2}+U_{3}\left(S_{k}\right) \times C_{3}$

Subject to constraint: Rental Policy (P)

Our objective is to minimize rental cost of machines while minimizing the utilization time.

\section{ALGORITHM}

Step 1: Calculate the expected processing times

$$
A_{i j}=a_{i j} \times p_{i j} \forall i, j
$$

Step 2: Check the condition: either $A_{j 2} \leq A_{i 1}$ or $A_{i 2} \leq A_{j 3} \forall i, j$.

.i.e. either $\operatorname{Max}\left\{A_{j 2}\right\} \leq \operatorname{Min}\left\{A_{i 1}\right\}$ or $\operatorname{Max}$ $\left\{A_{i 2}\right\} \leq \operatorname{Min}\left\{A_{j 3}\right\} \forall i, j$.

If the conditions are satisfied then go to Step 3, else the data is not in the standard form.

Step 3: Introduce the two fictitious machines $G$ and $H$ with processing times $\mathrm{G}_{\mathrm{i}}$ and $\mathrm{H}_{\mathrm{i}}$ as

$$
G_{i}=A_{i 1}+A_{i 2}, H_{i}=A_{i 2}+A_{i 3} \forall i \text {. }
$$

Step 4: Obtain the sequence $\mathrm{S}_{1}$ (say) by applying Johnson (1954) algorithm on machines G \& H.

Step 5: Obtain other sequences by putting 2nd, 3rd... nth jobs of the sequence $S_{1}$ in the 1st position and all other jobs of $S_{1}$ in the same order. Let these sequences be $\mathrm{S}_{2}, \mathrm{~S}_{3}, \mathrm{~S}_{4},-------, \mathrm{S}_{\mathrm{n}-1}$.

Step 6: Compute $\sum_{i=1}^{n} A_{i 1}, U_{2}\left(S_{k}\right), U_{3}\left(S_{k}\right)$ and

$$
R\left(S_{k}\right)=\sum_{i=1}^{n} A_{i 1} \times C_{1}+U_{2}\left(S_{k}\right) \times C_{2}+U_{3}\left(S_{k}\right) \times C_{3} \text { for }
$$

all the possible sequences $\mathrm{S}_{\mathrm{k}}(\mathrm{k}=1,2,3, \ldots \ldots, \mathrm{n})$.

Step 7: Find $\min \left\{R\left(s_{k}\right)\right\} ; k=1,2,3, \ldots . ., n$. Let it be minimum for the sequence $S p$, and then the sequence $S p$ will be the optimal sequence with rental cost $\mathrm{R}(S p)$.

\section{NUMERICAL ILLUSTRATION}

Consider 5 jobs, 3 machine flow shop problem with processing time associated with their respective probabilities as given in table 2 . The rental cost per unit time for machines $M_{1}, M_{2}$ and $M_{3}$ are 4 units, 6 units and 8 units respectively, under the rental policy $P$. Our objective is to obtain an optimal sequence of the jobs to minimize the rental cost of the machines.

TABLE II: THE PROCESSING TIMES WITH PROBABILITIES
\begin{tabular}{|c|c|c|c|c|c|c|}
\hline Jobs & \multicolumn{2}{|c|}{ Machine $M_{1}$} & \multicolumn{2}{|c|}{ Machine ${ }^{\mathrm{M} 2}$} & \multicolumn{2}{|c|}{ Machine $M_{3}$} \\
\hline$i$ & $a_{i 1}$ & $p_{i 1}$ & $a_{i 2}$ & $p_{i 2}$ & $a_{i 3}$ & $p_{i 3}$ \\
\hline 1 & 50 & 0.1 & 15 & 0.2 & 25 & 0.2 \\
\hline 2 & 25 & 0.2 & 10 & 0.4 & 40 & 0.1 \\
\hline 3 & 20 & 0.3 & 20 & 0.1 & 25 & 0.2 \\
\hline 4 & 24 & 0.2 & 10 & 0.2 & 20 & 0.3 \\
\hline 5 & 20 & 0.2 & 30 & 0.1 & 20 & 0.2 \\
\hline
\end{tabular}

Solution: The expected processing times $A_{i 1}, A_{i 2}$ and $A_{i 3}$ for machines $M_{1}, M_{2}$ and $M_{3}$ are

TABLE III: EXPECTED PROCESSING TIMES OF THE MACHINES

\begin{tabular}{|c|c|c|c|}
\hline Jobs & $A_{i 1}$ & $A_{i 2}$ & $A_{i 3}$ \\
\hline 1 & 5 & 3 & 5 \\
\hline
\end{tabular}




\begin{tabular}{|c|c|c|c|}
\hline 2 & 5 & 4 & 4 \\
\hline 3 & 6 & 2 & 4 \\
\hline 4 & 4.8 & 2 & 6 \\
\hline 5 & 4 & 3 & 4 \\
\hline
\end{tabular}

Here, we observe that $A_{i 2} \leq A_{j 3} \forall i, j$.

The two fictious machines with processing times $G_{i}$ and $H_{i}$ are

TABLE IV: THE PROCESSING TIME FOR TwO FICTIOUS MACHINES

\begin{tabular}{|c|c|c|c|c|c|}
\hline Jobs & 1 & 2 & 3 & 4 & 5 \\
\hline$G_{i}$ & 8 & 9 & 8 & 6.8 & 7 \\
\hline$H_{i}$ & 8 & 8 & 7 & 8 & 7 \\
\hline
\end{tabular}

Using Johnson (1954) procedure, the sequence with minimum makespan is $\mathrm{S}_{1}: 4-1-3-5-2$.

Other feasible sequences which may correspond to minimum rental cost are $\mathrm{S}_{2}: 1-4-3-5-2, \mathrm{~S}_{3}: 3-4-1$ $-5-2, \mathrm{~S}_{4}: 5-4-1-3-2, \mathrm{~S}_{5}: 2-4-1-3-5$.

The In-Out table flow time table for the sequence $\mathrm{S}_{1}: 4$ $-1-3-5-2$ is

TABLE V: THE IN-OUT FLOW TABLE FOR $S_{1}$

\begin{tabular}{|c|c|c|c|}
\hline Jobs & Machine $M_{1}$ & Machine $M_{2}$ & Machine $M_{3}$ \\
\hline$i$ & In -Out & In - Out & In - Out \\
\hline 4 & $0.0-4.8$ & $4.8-6.8$ & $6.8-12.8$ \\
\hline 1 & $4.8-9.8$ & $9.8-12.8$ & $12.8-17.8$ \\
\hline 3 & $9.8-15.8$ & $15.8-17.8$ & $17.8-21.8$ \\
\hline 5 & $15.8-19.8$ & $19.8-22.8$ & $22.8-26.8$ \\
\hline 2 & $19.8-24.8$ & $24.8-28.8$ & $28.8-32.8$ \\
\hline
\end{tabular}

Therefore, the completion time for $\mathrm{S}_{1}=\mathrm{CT}\left(\mathrm{S}_{1}\right)=32.8$ units

Utilization time of machine $\mathrm{M}_{2}=\mathrm{U}_{2}\left(\mathrm{~S}_{1}\right)=24.0$ units

Utilization time of machine $\mathrm{M}_{3}=\mathrm{U}_{3}\left(\mathrm{~S}_{1}\right)=26.0$ units

Hence, the Rental cost of machines for sequence of jobs $\mathrm{S}_{1}=454.4$ units.

Similarly, we can have for the sequences

$\mathrm{S}_{2}: \mathrm{CT}\left(\mathrm{S}_{2}\right)=32.8, \mathrm{U}_{2}\left(\mathrm{~S}_{2}\right)=23.8, \mathrm{U}_{3}\left(\mathrm{~S}_{2}\right)=24.8, \mathrm{R}\left(\mathrm{S}_{2}\right)$ $=443.6$ units.

$\mathrm{S}_{3}: \mathrm{CT}\left(\mathrm{S}_{3}\right)=34.0, \mathrm{U}_{2}\left(\mathrm{~S}_{3}\right)=22.8, \mathrm{U}_{3}\left(\mathrm{~S}_{3}\right)=26.0, \mathrm{R}\left(\mathrm{S}_{3}\right)$ $=447.2$ units.

$\mathrm{S}_{4}: \mathrm{CT}\left(\mathrm{S}_{4}\right)=32.8, \mathrm{U}_{2}\left(\mathrm{~S}_{4}\right)=24.8, \mathrm{U}_{3}\left(\mathrm{~S}_{4}\right)=25.8, \mathrm{R}\left(\mathrm{S}_{4}\right)$ $=457.6$ units.

$\mathrm{S}_{5}: \mathrm{CT}\left(\mathrm{S}_{5}\right)=33.0, \mathrm{U}_{2}\left(\mathrm{~S}_{5}\right)=22.8, \mathrm{U}_{3}\left(\mathrm{~S}_{4}\right)=24.0, \mathrm{R}\left(\mathrm{S}_{5}\right)$ $=431.2$ units.

Therefore, Min $\left\{\mathrm{R}\left(\mathrm{S}_{\mathrm{k}}\right)\right\}=431.2$ units and is for the sequence of jobs $\mathrm{S}_{5}$.
Hence the sequence $S_{5}: 2-4-1-3-5$ is the optimal sequence with minimum rental cost 431.2 units although the makespan for $\mathrm{S}_{5}$ is not minimum.

\section{CONCLUSION}

The algorithm proposed in this paper for specially structured three stage flow shop scheduling problem to minimize the rental cost of the machines gives an optimal sequence with minimum total rental cost of machines irrespective of total elapsed time. The algorithm proposed by Johnson (1954) to find an optimal sequence to minimize the makespan/ Total elapsed time is not always corresponds to minimum total rental cost of the machines .Hence proposed algorithm is more efficient to minimize the rental cost of the machines under a specified rental policy $(\mathrm{P})$ as compared with the algorithm proposed by Johnson (1954).

\section{REFERENCES}

[1] S. M. Johnson, "Optimal two and three stage production schedule with set up times included," Naval Research Logistic, vol. 1, no. 1, pp. 61-68, 1954.

[2] E. Ignall and L. Schrage, "Application of the branch and bound technique to some flow shop scheduling problems," Operation Researc, no. 13, pp. 400-412, 1965.

[3] P. C. Bagga, "Sequencing in a rental situation," Journal of Canadian Operation Research Society, no. 7, pp. 152-153, 1969.

[4] J. N. D. Gupta, "Optimal Schedule for specially structured flow shop," Naval Research Logistic, vol. 22, no. 2, pp. 255-269, 1975.

[5] W. Szware, "Special cases of the flow shop problems," Naval Research Logistic, vol. 22, no. 3, pp. 483-492, 1977.

[6] P. L. Maggu and G. Das, "On n x 2 sequencing problem with transportation time of jobs," Pure and Applied Mathematika Sciences, no. 3, pp. 12-16, 1981.

[7] J. N. D. Gupta, "Two stage hybrid flow shop scheduling problem," J. Ope. Res. Soc., vol. 39, no. 4, pp. 359 - 364, 1988.

[8] L. Narian and P. C. Bagga, "Minimizing hiring cost of machines in $\mathrm{n} \times 3$ flow shop problem," XXXI Annual ORSI Convention and International Conference on Operation Research and Industry 1998 Agra [India].

[9] T. P. Singh, K. Rajindra, and G. Deepak, "Optimal three stage production schedule the processing time and set times associated with probabilities including job block criteria," Proceedings of National Conference FACM, pp. 463-492, 2005.

[10] L. Narian and P. C. Bagga, "Two machine flow shop problem with availability constraint on each machine," JISSOR, vol. XXIV, no. 1-4, pp. 17-24, 2005.

[11] L. Narian and P. C. Bagga, "Scheduling problems in Rental Situation," Bulletin of Pure and Applied Sciences E.Mathematics and Statistics, no. 24, 2005.

[12] T. P. Singh and G. Deepak, "Minimizing rental cost in two stage flow shop, the processing time associated with probabilies including job block," Reflections de ERA, vol. 1, no. 2, pp. 107120,2005

[13] G. Deepak and S. Sameer, "Minimizing rental cost under specified rental policy in two stage flowshop, the processing time associated with probabilities including breakdown interval and Job-block criteria," European Journal of Business and Management, vol. 2, no. 3, pp. 85-103, 2011.

[14] G. Deepak, S. Sameer, and S. Bala, "Specially structured two stage flow shop scheduling to minimize the rental cost," International Journal of Emerging Trends in Engineering and Development, vol. 2, no. 1, pp. 206-215, 2012. 